\title{
Vancomycin-Resistant Lactococcus lactis 1A-1 Isolated from a Competitive Exclusion Product Transfers Vancomycin Resistance Genes to Staphylo- coccus aureus
}

\author{
R. Doug Wagner*, ${ }^{*}$, Dedeh Kurniasih-Rubin ${ }^{2}$ and Shemedia J. Johnson ${ }^{1}$ \\ ${ }^{I}$ Microbiology Division, HFT-250, USFDA National Center for Toxicological Research, 3900 NCTR Rd., Jefferson, AR \\ 72079, USA; ${ }^{2}$ Biology Department, Universitas Syiah Kuala, Banda Aceh, Indonesia
}

\begin{abstract}
A vancomycin-resistant Lactococcus lactis isolate 1A-1 from a competitive exclusion (CE) product contained plasmid-encoded van $A, B, C 1$, and $C 2 / 3$ genes. The L. lactis $1 \mathrm{~A}-1$ conjugatively transferred the genes to Staphylococcus aureus in vitro. CE product bacteria may be reservoirs for dissemination of van $A, B$, and $C$ genes to the human gastrointestinal microbiota.
\end{abstract}

\section{INTRODUCTION}

Vancomycin is a drug of last resort against antibioticresistant enterococci and methicillin-resistant staphylococci. Unfortunately, resistance to vancomycin is increasingly being reported $[1,2]$. Studies on the dissemination and selection of antimicrobial drug resistance have focused mainly on clinically relevant bacterial species, but commensal bacteria may act as reservoirs of antimicrobial drug resistance genes similar to those found in human pathogens [3]. The commensal reservoir bacteria can be present in the intestines of farm animals exposed to antimicrobial drugs [4], and subsequently may contaminate the raw meat produced from these animals. Therefore, antimicrobial drug resistance genes from non-pathogenic as well as from pathogenic organisms are medically important.

Competitive exclusion (CE) products are mixtures of bacteria that are applied to newly hatched poultry chicks for rapid establishment of a protective gastrointestinal (GI) tract microbiota, which can impart colonization resistance against the human food-borne pathogens Salmonella enterica and Campylobacter jejuni [5]. A CE product may be manufactured by anaerobic culture of the bacterial mixture in large fermentation batches. During the growth phase of the bacteria, they can come into contact with other species in the mixture. If conjugation occurs between these bacterial species, genes could be transferred from one to another. A Lactococcus lactis strain $1 \mathrm{~A}-1$ was isolated from a CE product that was resistant to vancomycin [6], which is atypical of the species [7]. It is possible that the L. lactis isolate acquired a vancomycin resistance gene from a vancomycin-resistant Enterococcus sp. that was present in the CE product [8]. In the present study, we hypothesize that the vancomycinresistant $L$. lactis isolate may have the potential to transfer resistance determinants to a $S$. aureus strain similar to those that normally transit the human GI tract [9]. The present

*Address correspondence to this author at the Division of Microbiology, National Center for Toxicological Research, HFT-250, 3900 NCTR Rd., Jefferson, AR 72022, USA; Tel: (870) 543-7434; Fax: (870) 543-7307; E-mail: doug.wagner@fda.hhs.gov study was conducted to identify the vancomycin resistance genes present in the L. lactis isolate. The ability of the $L$. lactis isolate to transfer vancomycin resistance genes by conjugation to $S$. aureus was also evaluated.

\section{MATERIALS AND METHODS}

\section{Bacterial Strains and Growth Conditions}

The vancomycin-resistant $L$. lactis gene donor and $S$. aureus transconjugants were grown at $30^{\circ} \mathrm{C}$ in MRS broth (Thermo Fisher Scientific, Houston, TX) supplemented with $30 \mu \mathrm{g} / \mathrm{ml}$ vancomycin (Sigma Chemical Co., St. Louis, MO) or in Elliker broth (Thermo Fisher) containing various concentrations of vancomycin at $30^{\circ} \mathrm{C}$. Chemically competent $E$. coli (Invitrogen, Grand Island, NY) was grown at $37^{\circ} \mathrm{C}$ in Luria Bertani (LB) broth (Invitrogen). S. aureus ATCC 25923 was grown at $37^{\circ} \mathrm{C}$ in MRS broth.

\section{Phenotypic Vancomycin Susceptibility Test}

A disk diffusion method was used for antibiotic susceptibility testing [10]. Trypticase soy agar (TSA) plates (REMEL Laboratories, Lenexa, KS) were inoculated over the entire surface with a cotton-tipped applicator moistened in a MRS broth (Thermo Fisher) suspension of L. lactis 1A1at a density of $10^{7} \mathrm{CFU} / \mathrm{ml}$ (a $1: 10$ dilution of a $0.5 \mathrm{McFar}-$ land standard). The disks of vancomycin $(30 \mu \mathrm{g})$ were applied to inoculated TSA plates, which were incubated overnight at $30^{\circ} \mathrm{C}$. Inhibition zone sizes of suspected vancomycin resistance gene-containing isolates were compared with zone sizes of bacteria that were susceptible to $30 \mu \mathrm{g} / \mathrm{ml}$ vancomycin in broth culture and E. faecium ATCC 51559, which contains the vanA gene and is resistant to $30 \mu \mathrm{g} / \mathrm{ml}$ vancomycin [11]. Control organisms were as follows: Enterococcus faecalis ATCC 51299 contained the vanB gene, Enterococcus gallinarum ATCC 49573 was used for the $v a n C_{1}$ gene, the van $_{2 / 3}$ genes were present in Enterococcus casseliflavus ATCC 25788, and no vancomycin resistance gene was present in Enterococcus faecalis ATCC 29212 [11].

\section{Curing of Episomally Encoded Antimicrobial Resistance}

To determine if the resistance genes were carried by a plasmid, L. lactis 1A-1 was grown in MRS broth for 15 days 
in the presence of $10 \mu \mathrm{g} / \mathrm{ml}$ acridine orange [12]. Following repeated exposure to the curing agent, the bacteria were diluted in MRS broth and spread on MRS agar plates. The isolated colonies were replica-plated with nitrocellulose filters (Schleicher and Schuell, Keene, NH) to MRS agar plates without and with $30 \mu \mathrm{g} / \mathrm{ml}$ vancomycin. Susceptible colonies were tested by PCR to verify loss of the vanA gene. The isolate sensitivity to antibiotics was examined by the disk diffusion method.

\section{Mating Experiments}

A filter mating technique [13] was used to assess whether L. lactis 1A-1 could transfer vancomycin resistance by conjugation to $S$. aureus ATCC 25923. Bacteria were grown overnight in brain-heart infusion (BHI) broth (REMEL Laboratories). Donor (L. lactis 1A-1) and recipient $(S$. aureus) cells were mixed at a one to one ratio and incubated at $30^{\circ} \mathrm{C}$ for four hours in BHI broth. The cells were collected by suction filtration onto $0.45 \mu \mathrm{m}$ cellulose acetate filters (Millipore Corp., Bedford, MA) and the filters were placed onto trypticase soy agar plates containing 5\% sheep blood and $6 \mu \mathrm{g} / \mathrm{ml}$ vancomycin. The plates were incubated overnight at $37^{\circ} \mathrm{C}$. Bacteria were recovered from the plates and filters by rinsing with BHI broth. Vancomycin-resistant colonies of the recipient $S$. aureus were subcultured on BHI agar containing $30 \mu \mathrm{g} / \mathrm{ml}$ of vancomycin. DNA was isolated from resistant recipients and tested by PCR for the presence of vancomycin resistance genes for verification of resistance mechanism transfer.

\section{Screening, Isolation, Cloning and Sequencing Analysis of Vancomycin Resistance Genes}

Existing PCR methods were used for detection of genes encoding vancomycin resistance $[11,14]$. Genomic DNA from the L. lactis and $S$. aureus isolates was isolated using the Wizard Genomic DNA isolation kit (Promega, Madison, WI) and plasmid DNA was isolated using the technique described by Anderson and McKay [15]. The vanA gene sequences on the plasmid DNA were isolated by PCR (forward primer: 5' -GGG AAA ACG ACA ATT GC-3', reverse primer: 5' -GTA CAA TGC GGC CGT TA-3') and the products were inserted into the Eco RI polylinker site of a pCR2.1-TOPO cloning vector, as described in the manufacturer's instructions (Invitrogen). E. coli DH5 $\alpha$ cells (Invitrogen) were transformed with the recombinant plasmids. The inserted resistance genes were sequenced and gene sequences were submitted to GenBank BLAST searches [16] to determine if they were homologous to known resistance genes (i.e., van A). The PCR analyses [11] were used to detect van $A, v a n B, v a n C_{1}$, and $v a n C_{2 / 3}$, and the fragments lengths of the PCR product bands on $2 \%$ agarose electrophoresis gels were compared with a $100 \mathrm{bp}$ ladder (Invitrogen).

\section{RESULTS}

\section{Antimicrobial Susceptibility}

The L. lactis 1A-1 isolated from the competitive exclusion product was resistant to vancomycin $(30 \mu \mathrm{g} / \mathrm{ml})$, when examined by the disk diffusion assay and compared to susceptible bacteria (Table 1). The isolate was also able to grow in Elliker broth containing $1500 \mu \mathrm{g} / \mathrm{ml}$ vancomycin. The $S$. aureus transconjugants also exhibited smaller zones of inhibition than the original recipient strain (Table 1).
Table 1. Phenotypic Detection of Vancomycin Resistance by L. lactis Donor and S. aureus Transconjugants

\begin{tabular}{|c|c|}
\hline Isolate & Growth inhibition zone diameter $(\mathbf{m m})$ \\
\hline \hline L. lactis $1 \mathrm{~A}-1$ & 0 \\
\hline L. lactis $1 \mathrm{~A}-1$ after curing & 22 \\
\hline S. aureus $\mathrm{wt} *$ & 20 \\
\hline S. aureus tc & 15 \\
\hline S. aureus tc after curing & 21 \\
\hline E. faecalis ATCC 51299 & 9 \\
\hline E. faecalis ATCC 29212 & 18 \\
\hline
\end{tabular}

$*_{\mathrm{wt}}=$ wild type, $\mathrm{tc}=$ transconjugant.

\section{Mating Experiments}

Conjugative transfer of high level vancomycin resistance from L. lactis 1A-1 to S. aureus ATCC 25923 (sensitive parent strain) was demonstrated in vitro. Five transconjugant clones were recovered that were resistant to $30 \mu \mathrm{g} / \mathrm{ml}$ of vancomycin, having inhibition disk zone diameters of $15 \mathrm{~mm}$, compared with a $20 \mathrm{~mm}$ zone diameter of the wild type $S$. aureus.

\section{Screening, Isolation, Cloning and Sequencing Analysis} for Vancomycin Resistance Genes

The presence of the vanA vancomycin resistance gene was detected in L. lactis $1 \mathrm{~A}-1$ and the $S$. aureus transconjugant, but not the wild type $S$. aureus recipient strain by PCR (Fig. 1). The nucleotide sequences of the vanA gene of $L$. lactis $1 \mathrm{~A}-1$ were $97 \%$ identical to those of the E. faecium

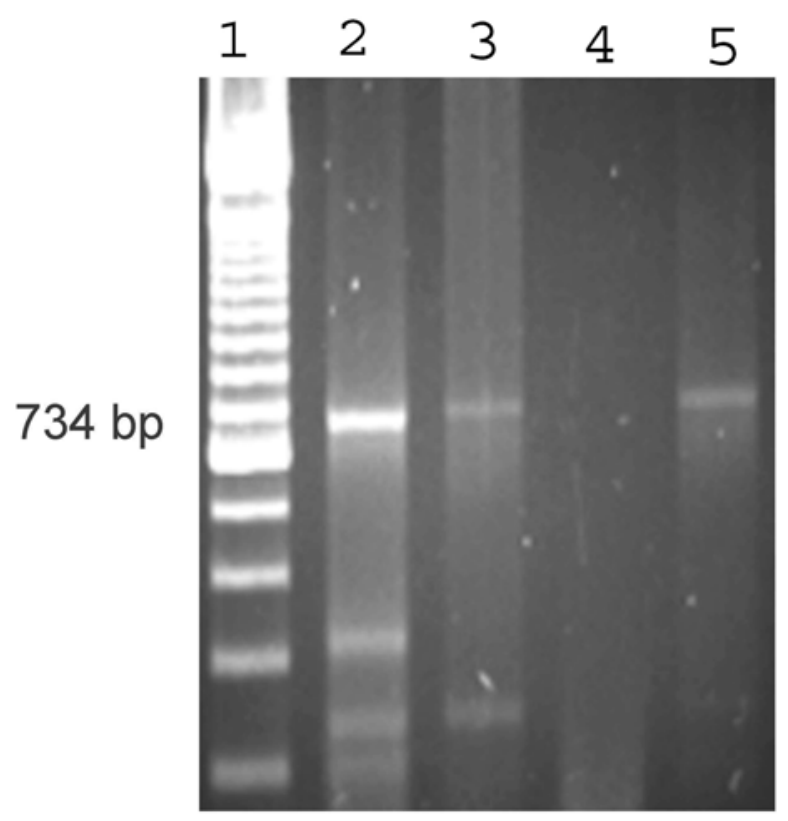

Fig. (1). Detection of the vanA gene in bacteria isolates by PCR. The gel lanes are: $1=$ molecular weight ladder, $2=$ L. lactis $1 \mathrm{~A}-1$, $3=S$. aureus transconjugant, $4=S$. aureus $25923,5=E$. faecium 51559 positive control. 


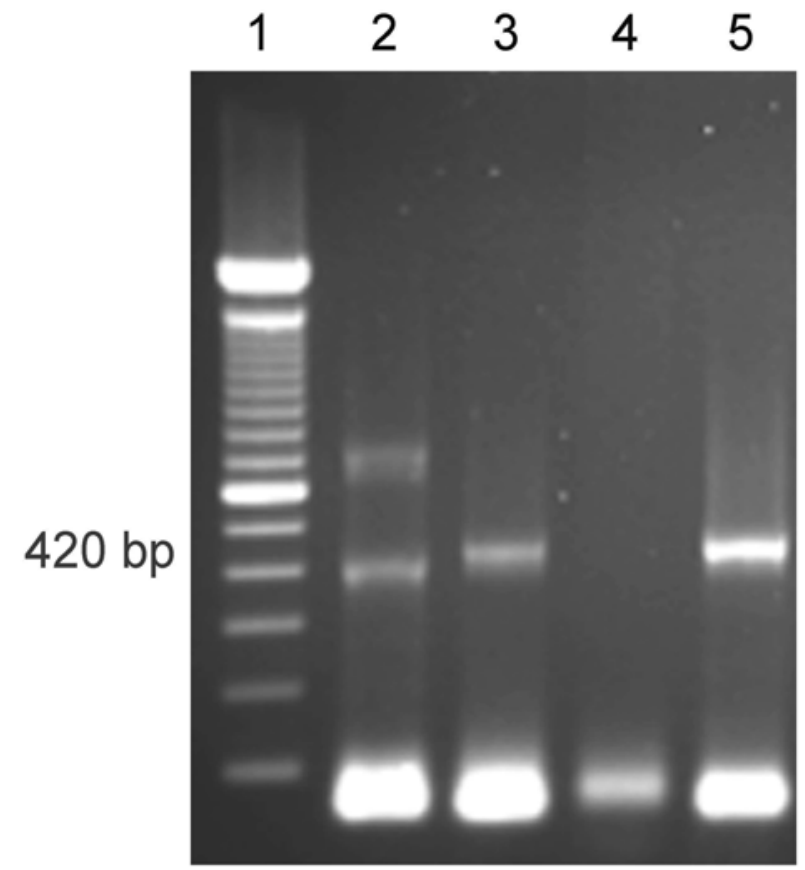

Fig. (2). The vanB gene was detected in the L. lactis donor and the $S$. aureus transconjugant by PCR. The gel lanes are: $1=$ molecular weight ladder, $2=$ E. faecalis 51299 positive control, $3=$ L. lactis $1 \mathrm{~A}-1,4=S$. aureus $25923,5=S$. aureus transconjugant.

strain F4/13 (54) in GenBank, according to a BLAST search (Accession no. EF206285.1). The L. lactis 1A-1 isolate and the $S$. aureus transconjugants also had $v a n B$ gene sequences detectable by PCR (Fig. 2). The van $C_{1}$ (Fig. 3) and $v a n C_{2 / 3}$ (Fig. 4) genes were also detected in L. lactis $1 \mathrm{~A}-1$ and the $S$. aureus transconjugant, but not in the recipient wild type $S$. aureus. The van $C_{1}$ PCR product had $97 \%$ sequence identity with the vanC $C_{1}$ gene from Enterococcus gallinarum (Accession no. AY786180.1).

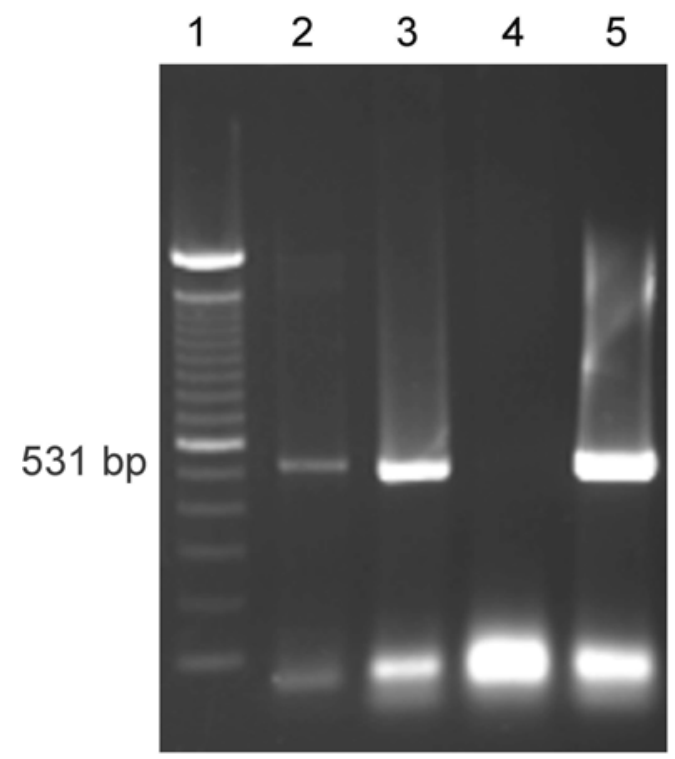

Fig. (3). The van $C_{1}$ gene was detected in the L. lactis donor and the $S$. aureus transconjugant by PCR. The gel lanes are: $1=$ molecular weight ladder, $2=$ L. lactis $1 \mathrm{~A}-1,3=S$. aureus transconjugant, $4=$ S. aureus $25923,5=$ E. gallinarum 49573 positive control.

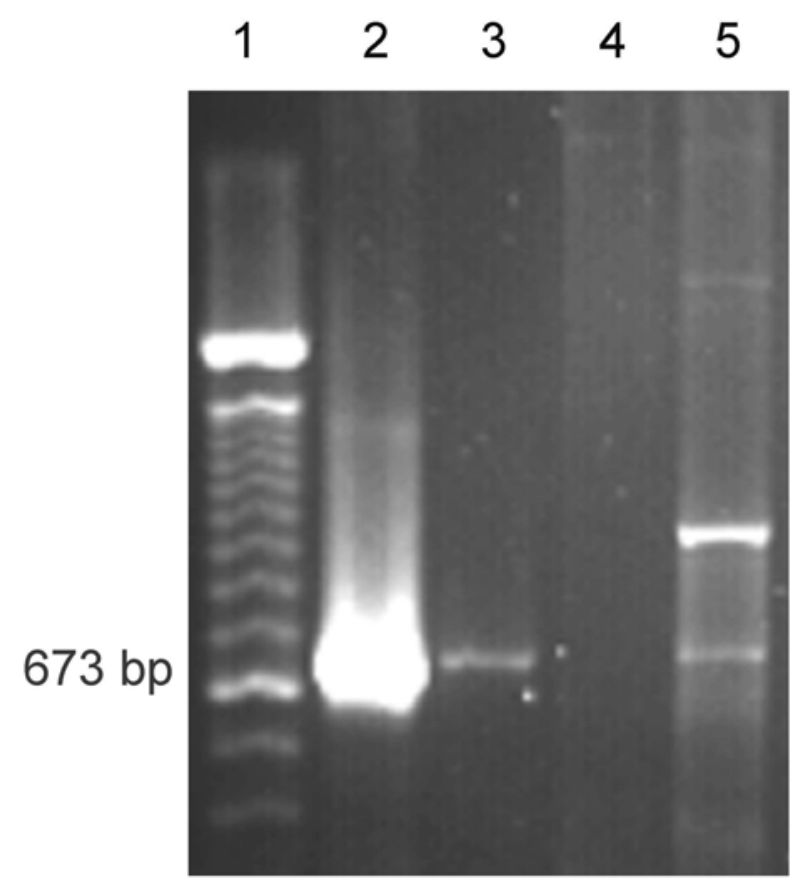

Fig. (4). The $v a n C_{2 / 3}$ genes were detected in the L. lactis donor and the $S$. aureus transconjugant by PCR. The gel lanes are: $1=$ molecular weight ladder, $2=L$. lactis $1 \mathrm{~A}-1,3=S$. aureus transconjugant, $4=S$. aureus 25923, 5 = Enterococcus casseliflavus 25788 positive control.

\section{Curing of Episomally Encoded Antimicrobial Resistance}

The acridine orange treatment yielded revertant $S$. aureus transconjugants at a rate of $86 \%$. The reversion rate of $L$. lactis $1 \mathrm{~A}-1$ was $36 \%$. As a control, E. faecium 51559 was also treated with acridine orange. It had a reversion rate of $93 \%$. The ability to make the bacteria susceptible to vancomycin by acridine orange treatment suggests that vanA was present on episomal DNA in L. lactis 1A-1 and the $S$. aureus transconjugant. Plasmid-cured L. lactis $1 \mathrm{~A}-1$ and the plasmid-cured $S$. aureus transconjugant were more susceptible than the uncured clones, as shown with the disk diffusion assay (Table 1).

\section{DISCUSSION}

The purpose of using CE products in poultry agriculture is to increase food safety by decreasing the incidence of adult animals reaching the human food supply contaminated with food-borne pathogens, such as Salmonella enterica and Campylobacter jejuni. The documented ability of these products to competitively exclude food-borne pathogens is encouraging, but not if the $\mathrm{CE}$ bacteria themselves pose a food safety risk [5]. The scientific community is aware that antimicrobial drug resistance genes can be mobilized between bacterial species in the gastrointestinal tract [17]. The vancomycin-resistant enterococci (VRE), once thought to be exclusively a problem associated with the medical use of glycopeptide drugs [18], are now being found in environmental sources that may contribute to the growing threat of VRE in and outside of the clinical setting [19]. CE products could contain VRE that transfer vancomycin resistance to other bacteria in the products during manufacture and to bacteria in the GI tracts of human poultry consumers. VRE have 
the ability to conjugatively transfer vancomycin resistance genes to Staphylococcus aureus in vitro [13]. Since S. aureus is a normal constituent of human microbiota, the presence of VRE in poultry may have the potential to transform $S$. aureus in the microbiota of consumers, essentially infecting them with this troublesome opportunistic pathogen.

In the present study, we found a vancomycin-resistant $L$. lactis in a commercial $\mathrm{CE}$ product that may have acquired the vanA gene from a VRE reported to be present in the CE product [20]. We confirmed that $L$. lactis $1 \mathrm{~A}-1$ contained a vanA gene on a high molecular weight plasmid. The van A gene was conjugatively transferred to $S$. aureus in vitro, suggesting that this activity could occur in vivo in a human poultry consumer. We also observed PCR products of other vancomycin resistance genes that may have been transferred from $L$. lactis $1 \mathrm{~A}-1$ to $S$. aureus, including $\operatorname{van} B$, $\operatorname{van} C_{1}$, and van $C_{2 / 3}$. These latter genes are associated with intermediate levels of resistance to vancomycin, while vanA is usually required for high resistance levels greater than $30 \mu \mathrm{g} / \mathrm{ml}$ [21]. In fact, $L$. lactis $1 \mathrm{~A}-1$ was resistant to extremely high concentrations, up to $1500 \mu \mathrm{g} / \mathrm{ml}$. The vanA [22], van $B_{1 / 2}$ [23, 24], $v a n C_{1}$, and $\operatorname{van} \mathrm{C}_{2 / 3}$ [11] genes have been reported on different conjugative DNA elements from different species of bacteria. Detection of multiple vancomycin resistance genes on the same conjugatively transferred element is uncommon. The co-culture methods used to produce some CE products may promote higher rates of gene transfer than the GI tract environment. Several reports indicate that factors normally present in the diet and the GI tract environment may inhibit horizontal gene transfer events, making the risk of this phenomenon less than might be otherwise expected $[18,25,26]$.

The nature of lactococci and enterococci appears to be that they can pass genes to each other. Horizontal gene transfer rates of mobilizable plasmids from L. lactis to E. faecalis have been measured in the digestive tracts of gnotobiotic mice at 3-4 $\log _{10} \mathrm{CFU} / \mathrm{g}$ feces [27]. Evidence also exists for the ability of lactococci to transfer genes to Enterobacteriaceae [28], so it is unclear how widely L. lactiscontaminated poultry meat could spread vancomycin resistance genes in the GI tracts of human consumers.

\section{CONCLUSION}

In the present study, multiple vancomycin resistance genes were transmissible by a $L$. lactis isolate from a $\mathrm{CE}$ product to a typical $S$. aureus that could be present in the GI tract of a human consumer. From the results presented in this study, it seems prudent to be concerned about the presence of transferable vancomycin resistance genes in live microbial animal feedstuffs and human food additives that contain enterococci and lactococci.

\section{ACKNOWLEDGEMENTS}

The authors acknowledge the reviewing efforts of Drs. Carl E. Cerniglia, Saeed Khan, and Bruce Erickson. Dedeh Kurniasih Rubin and Shemedia J. Johnson were supported by fellowships from the Oak Ridge Institute for Science and Education. This work was funded by the U.S. Public Health Service. The views presented in this manuscript are not necessarily those of the Food and Drug Administration.

\section{REFERENCES}

[1] Iversen A, Kühn I, Franklin A, Möllby R. High prevalence of vancomycin-resistant enterococci in Swedish sewage. Appl Environ Microbiol 2002; 68: 2838-2842.

[2] Tenover FC, Biddle JW, Lancaster MV. Increasing resistance to vancomycin and other glycopeptides in Staphylococcus aureus. Emerg Infect Dis 2001; 7: 327-332.

[3] Patel R. Enterococcal-type glycopeptides resistance genes in nonenterococcal organisms. FEMS Microbiol Lett 1999; 185: 1-7.

[4] Witte W. Ecological impact of antibiotic use in animals on different complex microflora: environment. Int $\mathbf{J}$ Antimicrob Agents 2000; 14: 321-5.

[5] Wagner RD. Efficacy and food safety considerations of poultry competitive exclusion products. Mol Nutr Food Res 2006; 50: 1061-1071.

[6] Wagner RD, Cerniglia CE. Antimicrobial susceptibility patterns of competitive exclusion bacteria. Int J Food Microbiol 2005; 102: 349-353.

[7] Facklam RR, Sahm DF, Teixeira LM. Enterococcus. In: Murray PM, Baron EJ, Pfaller MA, Tenover FC, Yolken RH, Eds. Manual of clinical microbiology $7^{\text {th }}$ ed. Washington, DC. ASM Press. 1999: 298.

[8] Wagner RD, Paine DD, Cerniglia CE. Phenotypic and genotypic characterization of competitive exclusion products for use in poultry. J Appl Microbiol 2003; 94: 1098-1107.

[9] Naidoo J. Interspecific co-transfer of antibiotic resistance plasmids in staphylococci in vivo. J Hygiene 1984; 93: 59-66.

[10] Bauer AW, Kirby WMM, Sherris JC, Turck M. Antibiotic susceptibility testing by standardized single disk method. Am J Clin Pathol 1966; 45: 493-496.

[11] Khan SA, Nawaz MS, Khan AA, Hopper SL, Jones RA, Cerniglia CE. Molecular characterization of multidrug-resistant Enterococcus spp. from poultry and dairy farms: detection of virulence and vancomycin resistance gene markers by PCR. Mol Cell Probes 2005; 19: 27-34.

[12] Spengler G, Molnár A, Schelz Z, Amaral L, Sharples D, Molnár J. The mechanism of plasmid curing in bacteria. Curr Drug Targets 2006; 7: 823-841.

[13] Noble WC, Virani Z, Cree RGA. Co-transfer of vancomycin and other resistance genes from Enterococcus faecalis NCTC 12201 to Staphylococcus aureus. FEMS Microbiol Lett 1992; 93: 195-198.

[14] Dutka-Malen S, Evers S, Courvalin P. Detection of glycopeptides resistance genotypes and identification to the species level of clinically relevant enterococci by PCR. J Clin Microbiol 1995; 33: 2427.

[15] Anderson DG, McKay LL. Simple and rapid method for isolating large plasmid DNA from lactic streptococci. Appl Environ Microbiol 1983; 46: 549-552.

[16] Altschul S, Madden TL, Schäffer AA, et al. Gapped BLAST and PSI-BLAST: a new generation of protein database search programs. Nucleic Acids Res 1997; 25: 3389-3402.

[17] Gruzza M, Fons M, Ouriet MF, Duval-Iflah Y, Ducluzeau R. Study of gene transfer in vitro and in the digestive tract of gnotobiotic mice from Lactococcus lactis strains to various strains belonging to human intestinal flora. Microb Releases 1994; 2: 183-189.

[18] Chen HY, Hill RL, Kirk M, Casewell MW, Beighton D. Differential antimicrobial susceptibility between human and chicken isolates of vancomycin-resistant and sensitive Enterococcus faecium. Int J Antimicrob Agents 2002; 19: 39-46.

[19] Kruse H. Indirect transfer of antibiotic resistance genes to man. Acta Vet Scand 1999; Suppl 92: 59-65.

[20] Nisbet DJ, Corrier DE, DeLoach JR. Probiotic for control of Salmonella. US 5478557. 1995.

[21] Coombs GW, Kay ID, Steven RA, Pearman JW, Bertolattti D, Grubb WB. Should genotypic testing be done on all phenotypically vancomycin-resistant enterococci detected in hospitals? J Clin Microbiol 1999; 37: 1229-1230.

[22] Arthur M, Molinas C, Depardieu F, Corvalin P. Characterization of TN1546, a Tn3-related transposon conferring glycopeptide resistance by synthesis of depsipeptide peptidoglycan precursors in Enterococcus faecium BM4147. J Bacteriol 1993; 175: 117-127.

[23] Ballard SA, Pertile KK, Lim M, Johnson PDR, Grayson ML. Molecular characterization of vanB elements in naturally occurring gut anaerobes. Antimicrob Agents Chemother 2005; 49: 1688-1694.

[24] Launay A, Ballard SA, Johnson PDR, Grayson ML, Lambert T. Transfer of vancomycin resistance transposon Tn1549 from Clos- 
tridium symbiosum to Enterococcus spp. in the gut of gnotobiotic mice. Antimicrob Agents Chemother 2006; 50: 1054-1062.

[25] Salyers A, Shoemaker NB. Reservoirs of antibiotic resistance genes. Anim Biotechnol 2006; 17: 137-146.

[26] Maisonneuve S, Ouriet M-F, Duval-Iflah Y. Interrelationships between dairy product intake, microflora metabolism, faecal properties, and plasmid dissemination in gnotobiotic mice. Brit J Nutr 2002; 87: 121-129.
[27] Alpert C-A, Mater DDG, Muller M-C, Ouriet M-F, Duval-Iflah Y, Corthier G. Worst-case scenarios for horizontal gene transfer from Lactococcus lactis carrying heterologous genes to Enterococcus faecalis in the digestive tract of gnotobiotic mice. Environ Biosafety Res 2003; 3: 173-180.

[28] Bolotin A, Quinquis B, Sorokin A, Ehrlich DS. Recent genetic transfer between Lactococcus lactis and enterobacteria. J Bacteriol 2004; 186: 6671-6677.

(C) Wagner et al.; Licensee Bentham Open.

This is an open access article distributed under the terms of the Creative Commons Attribution License (http://creativecommons.org/licenses/by/2.5/), which permits unrestrictive use, distribution, and reproduction in any medium, provided the original work is properly cited. 